J. Lake Sci.(湖泊科学), 2009, 21(3): 434-440

http://www.jlakes.org. E-mail: jlakes@niglas.ac.cn

(C)2009 by Journal of Lake Sciences

\title{
贵州蒸发血蒸发量变化趋势及影响因素分析*
}

\author{
秦年秀, 陈 喜, 薛显武, 张志才 \\ (河海大学水文水资源与水利工程科学国家重点实验室, 南京 210098)
}

摘 要: 以贵州境内 18 个气象站 1961-2001 年逐日气象观测数据为基础, 采用 Mann-Kendal 非参数检验方法、相关分析和 主成分分析方法对贵州近 41 年来蒸发血蒸发量及其主要影响因子(太阳净辐射、气温、相对湿度和风速等)进行了相关性及趋 势性分析. 结果表明: 近 41 年来, 贵州年平均蒸发血蒸发量呈显著下降趋势, 通过 99\%的置信度检验, 蒸发量的下降主要表 现在冬、春、夏三季. 从区域分布来看, 蒸发血蒸发量整体上东部及西北部分地区显著减少, 其他地区趋势变化不明显. 蒸发 皿蒸发量下降的主要原因是太阳净辐射的显著下降.

关键词: 蒸发血蒸发量; 趋势分析; 气象因子; 贵州省

\section{Analysis of pan evaporation trend and its impact factors in Guizhou Province}

QIN Nianxiu, CHEN Xi, XUE Xianwu \& ZHANG Zhicai

(State Key Laboratory of Hydrology-Water Resources and Hydraulic Engineering, Hohai University, Nanjing 210098, P.R.China)

Abstract: Based on daily meteorological data of 18 observations from 1961 to 2001 within Guizhou Province, Mann-Kendall trend test, correlation analysis and principal component analysis were applied to determine trend of pan evaporation and its relation with meteorological factors (net solar radiation, temperature, relative humid, wind speed etc.). Analysis results demonstrate: pan evaporation presents a significant decrease trend in the 41 years (99\% confidence level). This decrease trend is especially more significant in winter, spring and summer seasons. Spatially, significant decrease of pan evaporation occurs in the east area and part of the west area, and seldom occurs in the other areas. The pan evaporation decrease is primarily resulted from reduction of net solar radiation.

Keywords: Pan evaporation; trend analysis; meteorological factors; Guizhou Province

随着人类活动影响加剧, 气候变化已成为国内外科学界关注的热点问题之一. 气候变化对水文水资 源影响评估主要集中在降水变化趋势以及气温、日照、湿度等气象因素变化导致蒸发量变化对水资源的 影响程度 ${ }^{[1-8]}$. 蒸发血蒸发量与水面蒸发之间存在很好的相关关系, 是水文、气象台站常规观测项目之一, 由于资料累积序列长、可比性好，长期以来，一直是水资源评价、水利工程设计和气候区划的重要参考 指标.

当全球平均气温升高时，通常会认为空气将变得干燥，陆面水体蒸发量也会增加. 但通过对近四五 十年蒸发血蒸发量变化分析, 全球许多地区的蒸发血蒸发量存在显著的下降趋势 ${ }^{[9-16]}$. 在中国大部分地 区，蒸发血蒸发量也都表现出明显的下降趋势，年蒸发血蒸发量的下降趋势主要发生在春、夏、冬季，空 间上以华东和中南地区最明显 ${ }^{[17-26]}$. 蒸发量减少的主要原因是日照百分率下降导致太阳辐射的减少. 近 40 年(1961-2000 年)长江全流域蒸发血蒸发量中下游地区比上游地区下降趋势显著, 长江流域年平均太 阳净辐射和风速的显著下降是年平均蒸发血蒸发量显著下降的主要原因 ${ }^{[23]}$.

* 国家重点基础研究发展计划项目(2006CB403200)、教育部科学技术研究重大项目(308012)和国家自然科学基金项目 (50679025)联合资助. 2008-09-25 收稿; 2008-11-12 收修改稿. 秦年秀, 女, 1976 年生, 博士研究生; E-mail: nanjingnancy@yahoo.com.cn. 
贵州省位于我国西南部，处于世界喀斯特集中分布的亚洲片区中心，是我国喀斯特分布面积最大、 发育最复杂的一个省区, 其喀斯特分布面积占全省面积的 $85.9 \%$, 其中出露的碳酸盐岩面积达 $15 \times 10^{4} \mathrm{~km}^{2}$, 占全省土地总面积的 $73.6 \%$. 由于受特殊地质、地貌、气候、水文等自然因素的影响，加之不合理的人类 开发活动, 致使贵州山区各种自然灾害频繁, 尤其是水土流失带来的石漠化生态环境问题, 严重影响该 地区社会经济可持续发展.

利用贵州省18个气象站实测资料, 分析贵州省41年(1961-2001年)来蒸发皿蒸发量变化趋势及其受气 象因子变化的影响程度. 对贵州水资源利用、生态与环境保护及自然灾害的预测预防具有重要意义.

\section{1 资料与方法}

贵州境内 18 个气象站(图 1)具有逐日蒸发量、气温、相对湿度、日照时数、风速、最低气温、最高 气温、水汽压、低云量、总云量和降水量等实测资料. 统计结果表明: 贵州省多年平均(1961-2001 年)蒸 发血 $(20 \mathrm{~cm}$ )蒸发量为 $1220 \mathrm{~mm}$, 其中, 春季 (3-5 月) $346.2 \mathrm{~mm}$, 约占全年 $28.5 \%$, 夏季 $(6-8$ 月)为 $463.3 \mathrm{~mm}$, 约占全年 38\%, 秋季(9-11 月) $262.4 \mathrm{~mm}$, 占 21.6\%, 冬季(12-2 月) $144.7 \mathrm{~mm}$, 占 $11.9 \%$.

本文利用 Mann-Kendall(简称 MK 法)非参数检验方法 ${ }^{[27-28]}$ 分析蒸发量及气象因子趋势性和突变性; 利用相关分析确定影响蒸发量的主要气象要素并利用主成分分析来计算主要气象因子对蒸散发量的贡献 率; 采用反距离权重插值法 IDW(Inverse Distance Weighted) ${ }^{[29]}$ 方法分析要素的空间分布, 为了得到贵州 地区完整插值结果, 增加了研究区域周边 17 个气象站点资料, 以保证边缘地区的插值精度.

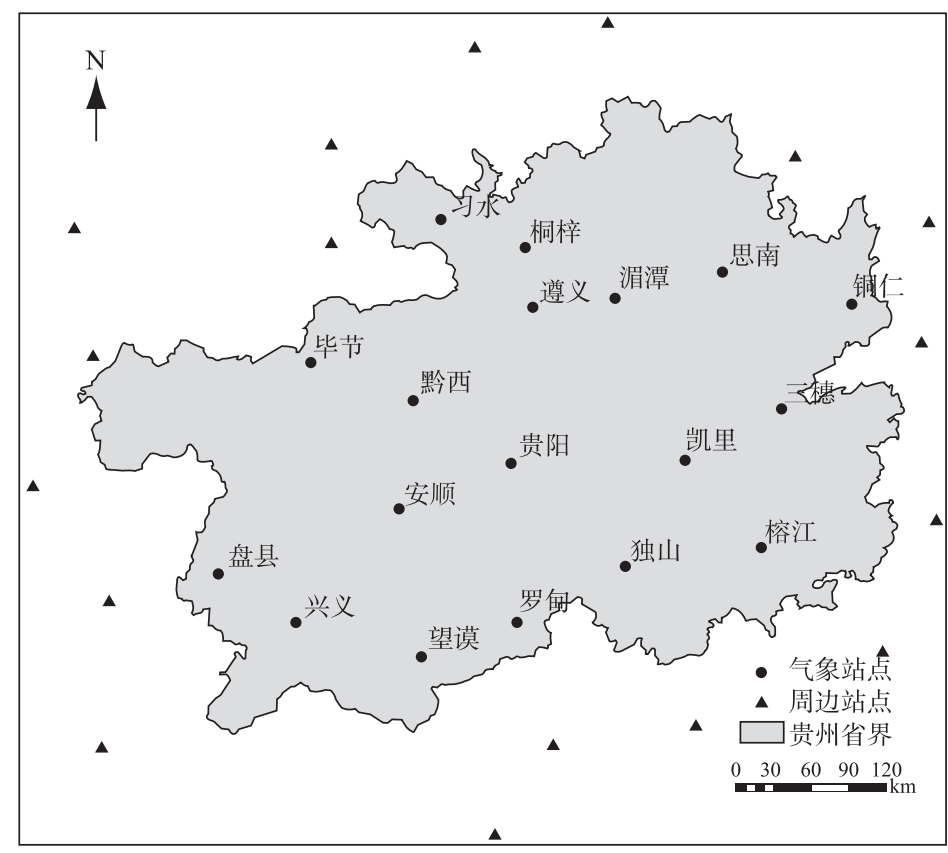

图 1 贵州省内及周边气象站点分布

Fig.1 Location of the meteorological stations in Guizhou Province

\section{2 结果分析}

\section{1 蒸发量年季变化趋势分析}

图 2a 为贵州境内气象站点实测年蒸发血蒸发量多年变化趋势, 表明近 41 年来贵州省蒸发血蒸发量 减少显著, 减少速率为 $29.7 \mathrm{~mm} / 10 \mathrm{a}$, MK 检测统计值高达-2.94, 通过了 99\%的置信度检验(表 1). 从年代 际平均值来看, 20 世纪 70 年代末至 80 年代初蒸发血蒸发量存在突变, MK 检测到该突变时间为 1978 年(图 
2b), 1978 年后蒸发血蒸发量减少显著. 1961-1977 年平均蒸发量比 1979-2001 年平均蒸发量高出 $77.51 \mathrm{~mm}$.

就各季节蒸发量变化趋势而言, 除秋季蒸发皿蒸发量变化趋势不显著外, 其他三季蒸发量变化态势 与年变化态势基本一致，均呈现明显下降趋势(表 1)，且都通过 $90 \%$ 以上的置信度检验. 就季节的年代际 变化而言(表 1), 春、夏、冬三季蒸发量变化速率差别较大, 春季呈现一直减少趋势, 夏、冬两季则表现 为波动式减少. 进一步对月蒸发量变化趋势分析可知(图 3), 春季蒸发量的显著减少以 3、4 月的贡献率最 大, 3 月和 4 月蒸发量减少趋势 MK 统计值分别为-1.57 和-1.86; 夏季以 7 月而冬季以 1 月的贡献率最大, 1 月和 7 月蒸发量减少趋势 MK 统计值分别为-1.95 和-2.38, 都通过 90\%显著性检验. 20 世纪 $80 、 90$ 年 代偏少, 转折年份都出现在 70 年代末或 80 年代初.
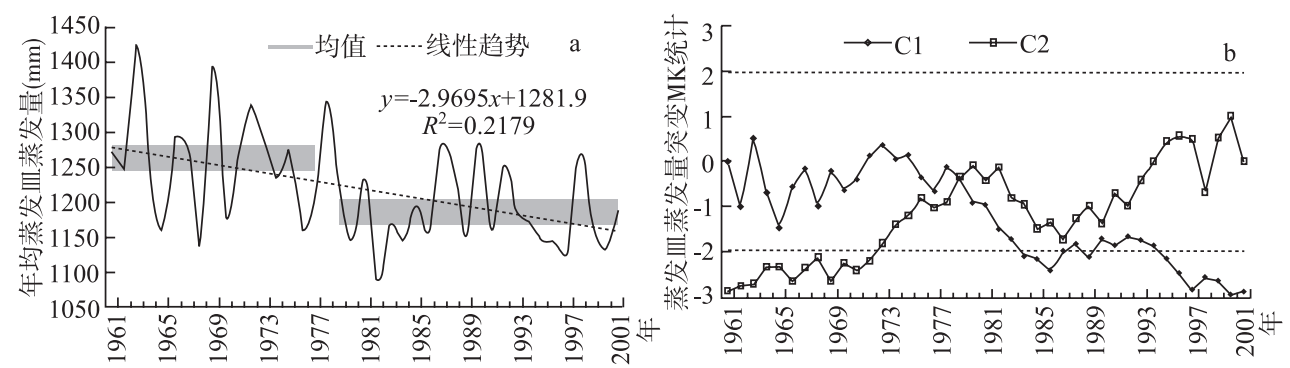

图 2 1961-2001 贵州省年均蒸发血蒸发量变化趋势(a)及 MK 突变检验(b) (C1: 原序列, C2: 逆序列) Fig.2 Annual linear trend and abrupt changes of pan evapotranspiration during 1961-2001 in Guizhou Province

表 1 1961-2001 年贵州省蒸发血蒸发量变化主要统计量

Tab.1 The main statistics of pan evapotranspiration change in Guizhou Province

\begin{tabular}{|c|c|c|c|c|c|c|}
\hline \multirow{2}{*}{ 时段 } & \multicolumn{4}{|c|}{ 均值 (mm) } & \multirow{2}{*}{$\begin{array}{c}\mathrm{MK} \\
\text { 统计量 }\end{array}$} & \multirow{2}{*}{$\begin{array}{c}\text { 显著性水平 } \\
(\%)\end{array}$} \\
\hline & $1961-1970$ 年 & 1971-1980 年 & 1981-1990 年 & 1991-2001 年 & & \\
\hline 春季 & 372.65 & 350.42 & 334.25 & 332.25 & -2.02 & 95 \\
\hline 夏季 & 471.59 & 468.35 & 476.79 & 439.15 & -2.11 & 95 \\
\hline 秋季 & 268.36 & 269.39 & 249.35 & 267.50 & -0.61 & \\
\hline 冬季 & 149.78 & 158.87 & 135. 26 & 138.44 & -1.42 & 90 \\
\hline 全年 & 1262.37 & 1247.03 & 1195.65 & 1177.34 & -2.94 & 99 \\
\hline
\end{tabular}

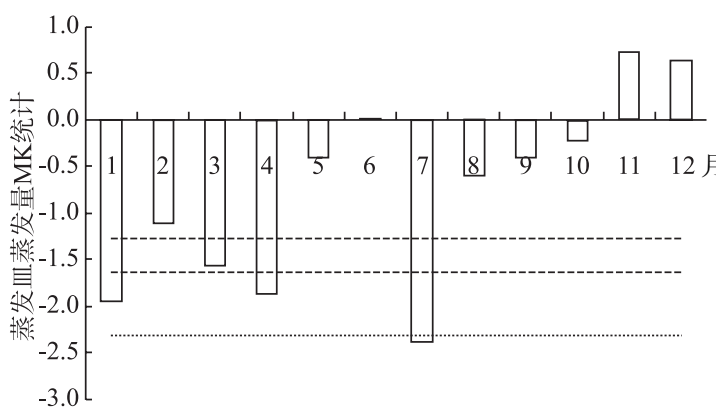

图 3 月蒸发血蒸发量变化趋势 MK 统计

Fig.3 Monthly trends of pan evapotranspiration

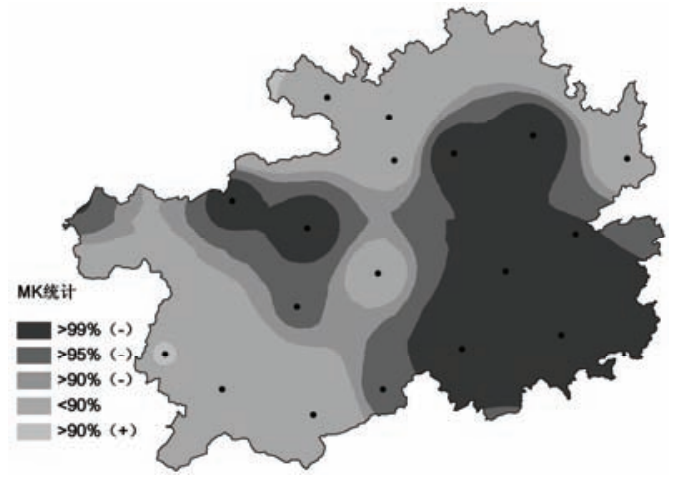

图 4 年平均蒸发血蒸发量变化趋势的空间分布

Fig.4 Spatial distribution for changes of annual mean pan evapotranspiration 


\section{2 蒸发血蒸发量变化空间分析}

贵州省年平均蒸发血蒸发量变化的空间分布来看(图 4), 蒸发血蒸发量变化趋势以明显减少为特点. 具体表现为, 东南及西北部分地区(如三穗、榕江、凯里、独山、思南、湄潭、毕节、黔西站)呈显著减少 趋势, MK 检验值都在-2.32 以上, 通过 $99 \%$ 置信度检验; 中部地区罗甸、安顺两站减少较明显, 通过 $95 \%$ 置信度检验; 东北及西南地区蒸发血蒸发量趋势变化不明显.

\section{3 蒸发血蒸发量主要影响因子及减少原因分析}

\section{1 蒸发血蒸发量影响因子分析}

为了进一步分析蒸发血蒸发量变化原因, 对蒸发血蒸发量与气候因子进行了相关分析(表 2). 从相关 程度分析来看, 贵州省蒸发血蒸发量与日照时数、低云量、日较差、最高气温、相对湿度、总云量的关 系较为密切. 蒸发血蒸发量与相对湿度、低云量、总云量具有较好的负相关性, 与低云量相关系数为 -0.8 , 春、夏季分别为 -0.84 和 -0.88 . 蒸发血蒸发量与日照时数、最高气温、气温平均日较差、平均风速呈正 相关. 与日照时数正相关最为显著, 相关系数达 0.89 , 春、夏两季高达 0.94 ; 其次与气温平均日较差, 相 关系数在 0.84 以上, 夏季高达 0.92 ; 与最高气温相关系数达 0.76 , 在蒸发强烈的春、夏季分别高达 0.93 和 0.92 ; 与平均风速相关系数为 0.49 .

表 2 贵州省蒸发量与气象因子相关系数

Tab.2 Correlation coefficient between pan-evaporation and meteorological elements in Guizhou Province

\begin{tabular}{cccccccccccc}
\hline 时段 & 日照 & 日较差 & 高温 & 低云量 & 相对湿度 & 总云量 & 风速 & 气温 & 降水 & 水汽压 & 低温 \\
\hline 春季 & 0.94 & 0.86 & 0.93 & -0.84 & -0.81 & -0.85 & 0.77 & 0.86 & -0.24 & 0.56 & 0.63 \\
夏季 & 0.94 & 0.92 & 0.92 & -0.88 & -0.86 & -0.79 & 0.32 & 0.72 & -0.76 & -0.27 & 0.01 \\
秋季 & 0.86 & 0.84 & 0.69 & -0.79 & -0.73 & -0.75 & 0.21 & 0.33 & -0.54 & -0.18 & -0.10 \\
冬季 & 0.82 & 0.81 & 0.75 & -0.76 & -0.77 & -0.7 & 0.3 & 0.54 & -0.63 & 0.19 & 0.28 \\
年均 & 0.89 & 0.84 & 0.71 & -0.80 & -0.67 & -0.62 & 0.49 & 0.43 & -0.35 & -0.03 & 0 \\
\hline
\end{tabular}

表 3 贵州省蒸发量主要影响因子分析

Tab.3 Factor analysis of meteorological elements in Guizhou Province

\begin{tabular}{cccc}
\hline 公共因子 & 高载荷指标 & 指标值 & 因子命名 \\
\hline 第一 & 低云量 & -0.921 & 能量因子 \\
& 日照 & 0.917 & \\
日较差 & 0.913 & 温度因子 \\
第二 & 低温 & 0.949 & \\
& 温度 & 0.924 & \\
& 水汽压 & 0.791 & 湿度因子 \\
第三 & 降水 & 0.904 & \\
& 湿度 & 0.716 & 风速因子 \\
第四 & 风速 & 0.955 &
\end{tabular}

这些气象要素之间也存在相关性，如降水量增加、空气相对湿度增大，蒸发量随之减少; 低云量的显 著增加减少了太阳辐射, 导致蒸发量减少. 进一步对各因子进行主成分分析(表 3), 最终确定 4 个主要因 子，它们对应的载荷量都在 70\%以上，其中能量因子对该区蒸发血蒸发量的减少贡献率达 $47.06 \%$, 其次 是温度因素, 贡献率为 $24.74 \%$, 再次是湿度因素, 为 12.53 , 第 4 个主要因子是风速因子, 四者累积贡献 率为 $90.91 \%$. 


\section{2 蒸发血蒸发量减少原因分析}

根据彭曼公式，反映影响蒸发量的主要气候因子不仅受局地气象要素如风速、相对湿度等的影响，还 会受到大尺度气候要素如日照、气温等的影响, 而日照时数、云量与当地接受的太阳辐射大小有密切关 系.

根据影响贵州省蒸发量的主要因子, 本文重点分析了太阳净辐射、气温、相对湿度和风速 4 种气象 因子的趋势变化(图 5 和表 4).

表 4 表明贵州省年均净辐射近 41 年来呈显著减少趋势，减少速率为 $-34.85 \mathrm{MJ} /\left(\mathrm{d} \cdot \mathrm{M}^{2}\right)$, 通过 $99 \%$ 以上 置信度检验. 在季节变化上表现为, 春夏减少明显, 减少速率分别为 $-10.19 \mathrm{MJ} /\left(\mathrm{d} \cdot \mathrm{M}^{2}\right)$ 和 $-19.96 \mathrm{MJ} /\left(\mathrm{d} \cdot \mathrm{M}^{2}\right)$, 减少趋势都通过 99\%以上置信度检验; 秋冬季节减少不明显. 区域年平均气温 1961-2001 年期间呈微弱 升温趋势, 升温速率为 $0.07^{\circ} \mathrm{C} / 10 \mathrm{a}$, 升温趋势不明显, 不具有统计意义. 升温主要表现在蒸发较弱的冬季, 冬季增温速率为 $0.2^{\circ} \mathrm{C} / 10 \mathrm{a}$, 通过 $95 \%$ 以上置信度检验. 年平均风速近 41 年来呈现轻微下降趋势, 下降速 率为 $-0.02 \mathrm{~m} /(\mathrm{s} \cdot 10 \mathrm{a})$, 下降趋势不明显, 不具有统计意义. 冬春季节减少速率分别为 $-0.04 \mathrm{~m} /(\mathrm{s} \cdot 10 \mathrm{a})$ 和 $-0.05 \mathrm{~m} /(\mathrm{s} \cdot 10 \mathrm{a})$, 冬季通过 $95 \%$ 以上置信度检验, 春季通过 $99 \%$ 以置信度检验, 下降趋势明显; 夏季增 加速率为 $0.03 \mathrm{~m} /(\mathrm{s} \cdot 10 \mathrm{a})$, 通过 90\%置信度检验. 1961-2001 年期间区域相对湿度, 除秋季下降较明显, 通 过 95\%以上置信度检验外, 无论年变化还是季节变化都不明显.
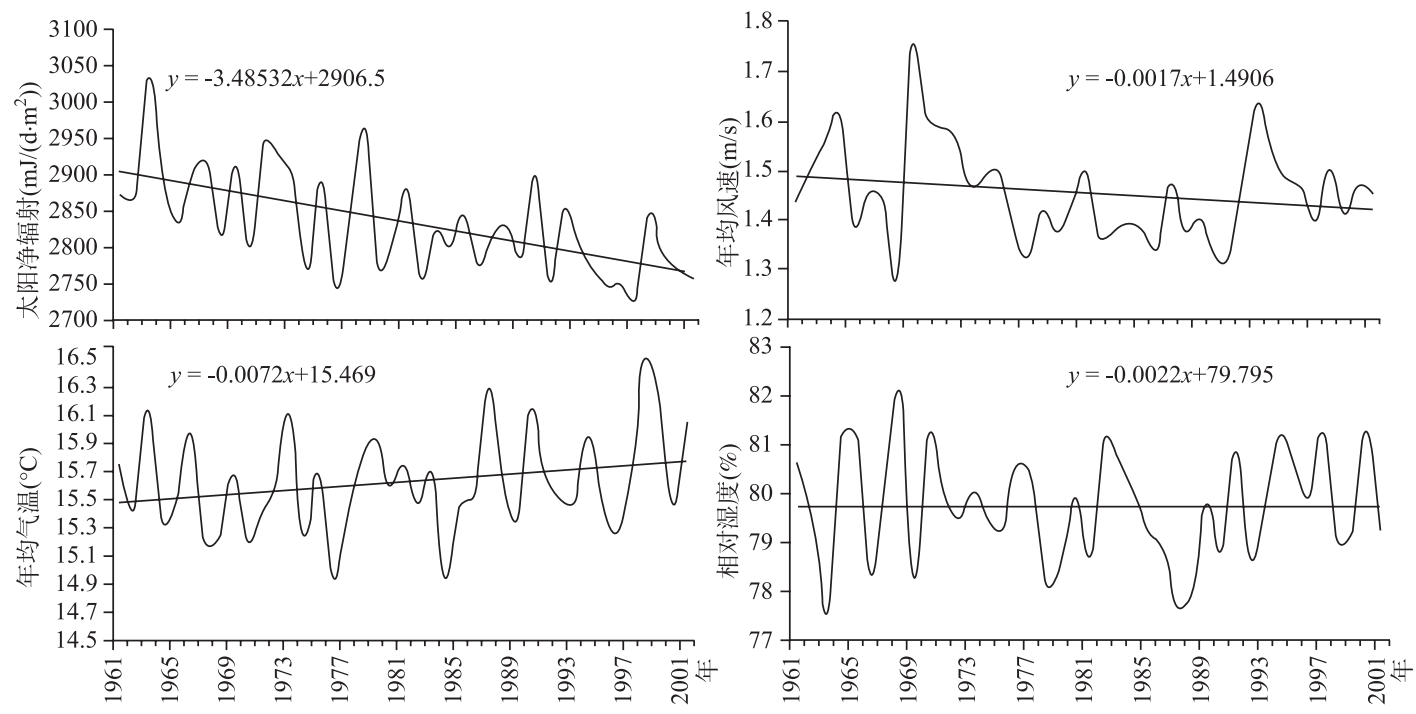

图 5 贵州省主要气象因子变化趋势

Fig.5 Annual linear trend of meteorological element in Guizhou Province

在太阳辐射到达地面的过程中, 会受到云、大气(包括基本大气成分、气溶胶和水汽等)以及自身变化 的影响, 目前国际上研究认为太阳净辐射的减少最主要是全球辐射减少所致 ${ }^{[11,16,30-32]}$, 有学者认为中国 地区太阳净辐射的减少主要是空气污染的增加引起的 ${ }^{[33-34]}$, 也有学者研究认为, 中国不同于世界其他地 区, 太阳辐射的减少不完全伴随云量和降水的增加，即两者不具有一致性 ${ }^{[31]}$. 低云量对太阳辐射具有遮 挡作用，在贵州地区，近41年来低云量呈现显著增加趋势，该地区低云量对太阳辐射减少的贡献有待进 一步定量研究.

一般认为日照时数与云量的观测精度较低, 而相对湿度、风速、气温的观测精度较高，与相对湿度、 风速、气温的观测精度相比日照时数与云量的观测精度尽管较低些，但文中分析可知近 41 年来贵州地区 相对湿度、风速、气温几乎没有表现出任何增加或减少的趋势变化, 同时太阳净辐射(日照时数)与云量却 呈现出显著地趋势变化. 太阳净辐射减少趋势MK统计为 -3.75 , 低云量增加趋势 $M K$ 统计为 3.62 , 增加或 
减少趋势非常显著. 因此, 即便考虑观测精度的影响, 也可以认为贵州省近 41 年来蒸发血蒸发量的显著 减少是云量增加导致的太阳净辐射显著下降所致.

表 4 贵州省主要气象因子 MK 分析及多年平均变化速率

Tab.4 MK statistics and the changing velocity of meteorological element in Guizhou Province

\begin{tabular}{|c|c|c|c|c|c|c|c|c|}
\hline \multirow{2}{*}{ 时段 } & \multicolumn{2}{|c|}{ 净辐射 } & \multicolumn{2}{|c|}{ 气温 } & \multicolumn{2}{|c|}{ 相对湿度 } & \multicolumn{2}{|c|}{ 风速 } \\
\hline & MK 值 & 变化速率 & MK 值 & 变化速率 & MK 值 & 变化速率 & MK 值 & 变化速率 \\
\hline 春 & -2.43 & -10.19 & -0.58 & 0.07 & 0.38 & 0.13 & -2.45 & -0.05 \\
\hline 夏 & -3.01 & -19.96 & 0.97 & 0.05 & 0.20 & 0.1 & 1.53 & 0.03 \\
\hline 秋 & -0.90 & -3.31 & 1.12 & 0.11 & -1.66 & -0.53 & -0.22 & -0.01 \\
\hline 冬 & -0.99 & -1.39 & 1.71 & 0.2 & 1.01 & 0.21 & -2.09 & -0.04 \\
\hline 年均 & -3.75 & -34.85 & 1.24 & 0.07 & -0.27 & -0.02 & -1.21 & -0.02 \\
\hline
\end{tabular}

\section{4 结论}

使用 MK 非参数检验方法，对贵州省近 41 年来蒸发血蒸发量及其影响因子的气候变化趋势分析，近 41 年来贵州省蒸发血蒸发量呈现显著的下降趋势, 尤其表现在春、夏和冬季. 其结论如下:

(1)贵州省蒸发皿蒸发量呈显著下降趋势, 年均减少速率为 $29.7 \mathrm{~mm} / 10 \mathrm{a}$, 减少趋势通过 $99 \%$ 以置 信度检验. 不同季节的分析表明, 蒸发血蒸发量的下降主要表现在春季、夏季和冬季, 秋季变化不明显. 就空间差异而言，东部地区基本表现为显著减少趋势，其他地区整体表现为减少趋势，但减少趋势变 化复杂.

(2)对 1961 至 2001 年间贵州省太阳净辐射、气温、湿度和风速的变化趋势分析表明, 贵州省云量增 加导致的太阳净辐射显著下降是蒸发血蒸发量显著减少的主要原因, 年内变化以春季和夏季太阳净辐射 减少趋势最为明显, 能量因子变化对蒸发的贡献率达 $47.06 \%$.

(3)虽然气温、风速、湿度等气象因子与蒸发血蒸发量相关程度高, 但这些因子无显著变化趋势, 对 蒸发血蒸发量减少影响不显著.

\section{5 参考文献}

[1] 刘渘秋. 黄淮海流域水危机与水资源可持续利用. 科技导报, 2002, (7): 51-54.

[2] Houghton J, Ding Y. Climate change: scientific basis. IPCC TAR Working Group 1, Cambridge University Press, 2001.

[3] 陈德亮, 高 歌. 气候变化对长江流域汉江和赣江径流的影响. 湖泊科学, 2003, 15(增刊): 105-113.

[4] 施雅风, 姜 剘, 王 俊等. 全球变暖对长江洪水的可能影响及其前景预测. 湖泊科学, 2003, 15(增刊): 1-15.

[5] 陈 喜, 苏布达, 姜 粀等. 气候变化对沅江流域径流影响研究. 湖泊科学, 2003, 15(增刊): 115-122.

[6] Stefan B, Marco G, Jiang Tong. Observed and interpolated precipitation trends and variability in the Yangtze Catchment Area. 湖泊科学, 2003, 15(增刊): 123-129.

[7] 秦年秀, 姜 形, 原 峰. 1990s 长江下游干流径流演变趋势. 湖泊科学, 2003, 15(增刊): 138-146.

[8] Zbigniew W, Kundzewicz. Flood risk growth under global change-Yangtze floods in perspective. 湖泊科学, 2003, 15(增刊): 155-165.

[9] Peterson TC, Golubev VS, Groisman PY. Evaporation losing its strength. Nature, 1995, 377: 687-688.

[10] Brutsanrt W, Parlange MB. Hydrological cycle explain the evaporation paradox. Nature, 1998, 396: 30-31.

[11] Roderick ML, Farquhar GD. The cause of decreased pan evaporation over the past 50 years. Science, 2002, 298: 1410-1411.

[12] Chattoopadhyay N, Hulme M. Evaporation and potential evapotranspiration in India under conditions of recent an $d$ future climate change. Agricultural and Forest Meteorology, 1997, 87: 55-72.

[13] Ramanathan V, Crutsen PJ, Kiehl JT et al. Aerosols, climate and the hydrological cycle. Science, 2001, 294: 2119-2124.

[14] Stanhill G, Cohen S. Global dimming: a review of the evidence for a widespread and significant reduction in global radiation 
with discussion of its probable causes and possible agricultural consequences. Agricultural and Forest Meteorology, 2001, 107: 255-278.

[15] Cohen S, Stanhill G. Evaporative climate changes at Bet-Dagun. Israel, 1964-1998. Agricultural and Forest Meteorology, 2002, 111(2): 83-91.

[16] Ohmura A, Wild M. Is the hydrological cycle accelerating? Science, 2002, 298: 1345-1346.

[17] 曾 燕, 邱新法, 刘昌明等. 1960-2000 年中国蒸发血蒸发量的气候变化特征. 水科学进展, 2007, 18(3): 311-318.

[18] 王 菱, 谢贤群, 李运生等. 中国北方地 40 年来湿润指数和气候干湿带界限的变化. 地理研究, 2004, 23(1): 45- 54.

[19] 刘 波，马柱国，丁裕国. 中国北方近 45 年蒸发变化的特征及与环境的关系. 高原气象, 2006, 25(5): 840-848.

[20] 邱新法, 刘昌明, 曾 燕. 黄河流域近 40 年蒸发血蒸发量的气候变化特征. 自然资源学报, 2003, 18(4): 437-441.

[21] 徐宗学, 和宛琳. 黄河流域近 40 年蒸发血蒸发量变化趋势分析. 水文, 2005, 25(6): 6-11.

[22] 郭 军, 任国玉. 黄淮海流域蒸发量的变化及其原因分析. 水科学进展, 2001, 16(5): 666-672.

[23] 王艳君, 姜 夰, 许崇育. 长江流域蒸发血蒸发量及影响因素变化趋势. 自然资源学报, 2005, 20(6): 864-870.

[24] 王国杰, 姜 彤, 王艳君等. 洞庭湖流域气候变化特征(1961-2003 年). 湖泊科学, 2006, 18(5): 470-475.

[25] 闵 骞, 刘 影. 鄱阳湖水面蒸发量的计算与变化趋势分析(1955-2004 年). 湖泊科学, 2006, 18(5): 452-457.

[26] 郭 华, 姜 形, 王国杰等. 1961-2003 年间鄱阳湖流域气候变化趋势及特征分析. 湖泊科学, 2006, 18(5): 443-451.

[27] 魏凤英. 现代气候统计诊断与预测技术. 北京: 气象出版社, 1999: 69-72.

[28] Thomas A. Spatial and temporal characteristics of potential evapotranspirpiration trends over China. International Journal of Climatology, 2000, 20: 381-396.

[29] 姚永慧, 潘志强, 孙英君等. Arc GIS地统计分析实用指南. 北京: Arc Info中国技术咨询与培训中心, 2002: 135-139.

[30] Michael LR, Graham DF. The cause of decreased pan evaporation over the past 50 years. Science, 2002, 298: 1410-1411.

[31] Liu B, Xu M, Henderson M et al. A spatial analysis of pan evaporation trends in China, 1955-2000. Geophysical Research, 2004, 109(2): 2660-2668.

[32] Xu CY, Gong LB, Jiang T et al. Decreasing reference evapotranspiration in a warming climate-a case of Changjiang (Yangtze River) catchment during 1970-2000. Advances in Atmospheric Sciences, 2006, 23(4): 513-520.

[33] Kaiser DP. Decreasing cloudiness over China: An updated analysis examining additional variables. Geophysical Research Letters, 2000, 27(15): 2193-2196.

[34] Kaiser DP. Assessing observed temperature and cloud amount trends for China over the last half of the twentieth century: What can the sunshine duration tell us? Report No. POO-109147, 2001: 12th Symposium on Global Change Studies, sponsored by U. S. Department of Energy. 